\title{
Suitability Analysis of Satellite Towns Using Saaty Model and Geographical Information System (GIS)
}

\author{
Selassie David Mayunga \\ Ardhi University, Dar es Salaam, Tanzania \\ Email: Magese58@gmail.com, magese22@yahoo.ca
}

How to cite this paper: Mayunga, S.D. (2018) Suitability Analysis of Satellite Towns Using Saaty Model and Geographical Information System (GIS). Journal of Data Analysis and Information Processing, 6, 1-14.

https://doi.org/10.4236/jdaip.2018.61001

Received: January 5, 2018

Accepted: February 25, 2018

Published: February 28, 2018

Copyright $\odot 2018$ by author and Scientific Research Publishing Inc. This work is licensed under the Creative Commons Attribution International License (CC BY 4.0).

http://creativecommons.org/licenses/by/4.0/

\begin{abstract}
Dar es Salaam is one of the fastest growing cities in East Africa, with a population of $4,364,541$ whose annual growth rate is $4.5 \%$. The population increase is mainly caused by rural to urban migration causing traffic congestion, unemployment, emerging of unplanned settlements, inadequate infrastructure, and social and housing services. In order to overcome these challenges there is an urgent need to establish and determine suitable locations of satellite towns to the outskirts of the central business district (CBD) to strengthen economic and social activities using reliable techniques. Selecting suitable locations of satellite towns has been determined by using distance from the CBD and population growth indicators. The limitations of using these indicators include unsuitable locations, which ultimately failed to attract economic growth in such areas. In this study, we introduce a new approach of selecting suitable location of satellite towns in fast growing cities. This approach uses Saaty Model and Geographic Information Systems techniques, whereby a pair wise comparison matrix, consistency index and consistency ratio are employed to determine suitable locations of satellite towns in Ubungo and Kinondoni Municipalities. Also, seven criteria were used to produce suitability maps for water, power line, road, communication line, elevation, slope and land use. The results obtained from this study show that about $5.31 \%$ of the area was classified as highly suitable, $29.82 \%$ as moderately suitable, $24.27 \%$ as marginally suitable and $40.6 \%$ permanently unsuitable. Locations of satellite towns determined using Saaty model was found to be on highly suitable areas whereas locations of satellite towns proposed by the Dar es Salaam master plan were located on marginally suitable areas. The study concludes that Saaty Model, if integrated with GIS, can be effectively used to determine suitable locations for satellite towns in urban areas.
\end{abstract}




\section{Keywords}

Saaty Model, Satellite Towns, Model Builder Toolbox and Decision Analysis

\section{Introduction}

Dar es Salaam is one of the fastest-growing cities in Sub-Saharan Africa with a population growth rate of $4.5 \%$ per year. According to the National Census and Housing population data of 2016, the population of Dar es salaam City was 5.5 million people and it is expected to reach 6.2 million by 2020 [1]. According to the report published by the Bank of Tanzania in 2012, the Dar es Salaam City's annual population growth rate stands at 4 per cent, which is above the country's 2.9 per cent [2]. Also, according to the African Development Bank prediction, the City population could reach 21.4 million by 2052 [3]. Despite the rapid growth of the City for the past 20 years, urban planning has been executed with various challenges. Residential, commercial areas and infrastructure are poorly planned, resulting into traffic congestion at the city centre, pollution and formulation of new unplanned settlements. According to the study conducted by the Confederation of Tanzanian Industries (CTI) in 2010, it was revealed that traffic congestion reduced the profit of the business community in the City by 20 per cent [4]. Despite Tanzania being undergoing rapid economic growth of about 7 per cent per annum, and per capital income rising from Tanzania Shillings 2000 to 3400 for the past 10 years, the City is lagging behind in terms of providing of better services, infrastructure and affordable housing to the residents.

One of the major causes of poor provision of basic services, infrastructure and affordable housing is the rapid population increase in the City. The rapid population increase is attributed to rural to urban migration of people from different regions. Rural to urban migration causes uncontrolled urban expansion, increase of unplanned settlements, and poor provision of social services. [5] identifies three major reasons for rural to urban migration, which includes psychological, social-economic and political pressure. [6] indentified poverty being the major cause of rural to urban migration. According to [6], lives in rural areas are unattractive particularly for the young generation, due to lack of social and economic activities. Rural to urban migration has negative impacts, including high cost of land and housing. High cost of land and housing is exerted by market forces and unrestrictive framework from local authorities. Also, rural to urban migration has lead to high unemployment in the City and shortage of social services, causing economic decline in rural areas as manpower is not fully utilized in rural areas. The major reason for the economic decline in rural is the failure of the rural communities to fully utilized land and other resources available for economic growth.

Urban planning in Tanzania has been conducted using "stakeholder-based" 
approach or commonly known as Strategic Urban Development Planning (SUDP) [7]. The stakeholder-based approach was adopted in 1995 on the assumption that it would be more effective in guiding urban expansion and responsive to existing urban planning challenges. In 2007 the SUDP approach was abandoned and urban planners returned to master planning approach which was adopted before 1990. [7] pointed out that the major reasons for the abandonment of SUDP were financial constraints and urban planning been considered as non priority. Consequently, the implementation of most urban plans were ignored or completely abandoned. Failure in implementing prepared urban plans in most urban areas in the country resulted into formation of informal settlements including Dar es Salaam City. In 2016 the draft master plan of Dar es Salaam City was announced symbolizing the return to master planning approach. The new draft master plan proposed six satellite towns at the outskirts of the City CBD. The proposed six satellite towns are Mji Mwema, Kimbiji and Kongowe in Temeke Municipality, Pugu Kajiungeni in the Ilala Municipality, Luguruni and Bunju in Kinondoni Municipality. Therefore, the objective of the satellite town is to decongest Dar es Salaam City centre, improve social, infrastructure, economic and environmental services to the community.

\section{Study Area}

The study areas for suitability analysis of satellite towns are Kinondoni and Ubungo Municipalities. Kinondoni Municipality is located in the northern part of Dar es Salaam City. The population is 1,466,591 and administratively it has 13 wards. Ubungo is a new municipality located in the western part of the city. The population is 1,031,349 and has 14 wards. Figure 1 Show the location of Kinondoni and Ubungo municipalities.

Kinondoni and Ubungo Municipalities were selected to undertake this study based on the fact that the rate of rural to urban migration in Dar es Salaam keeps on rising every year and there are more people living in the City particularly in Ubungo and Kinondoni Municipality. This means that plans need to put in place to de-congest the city's central business district by planning and establishing satellite towns.

\section{Related Studies on Satellite Towns}

Satellite City or Satellite town is the concept which was first introduced by [8] in 1915. The concept was then adopted by town planners as an approach to relive concentration of people and economic activities from the centre of big Cities. A satellite town or satellite city is defined as smaller metropolitan areas which are located near to larger metropolitan areas, but independent on services and infrastructure [9]. The establishment of satellite towns in the outskirts of the city offers a solution in reducing traffic congestion at the city centre, strengthening socio-economic activities, and reducing expansion and formation of new unplanned settlements. 


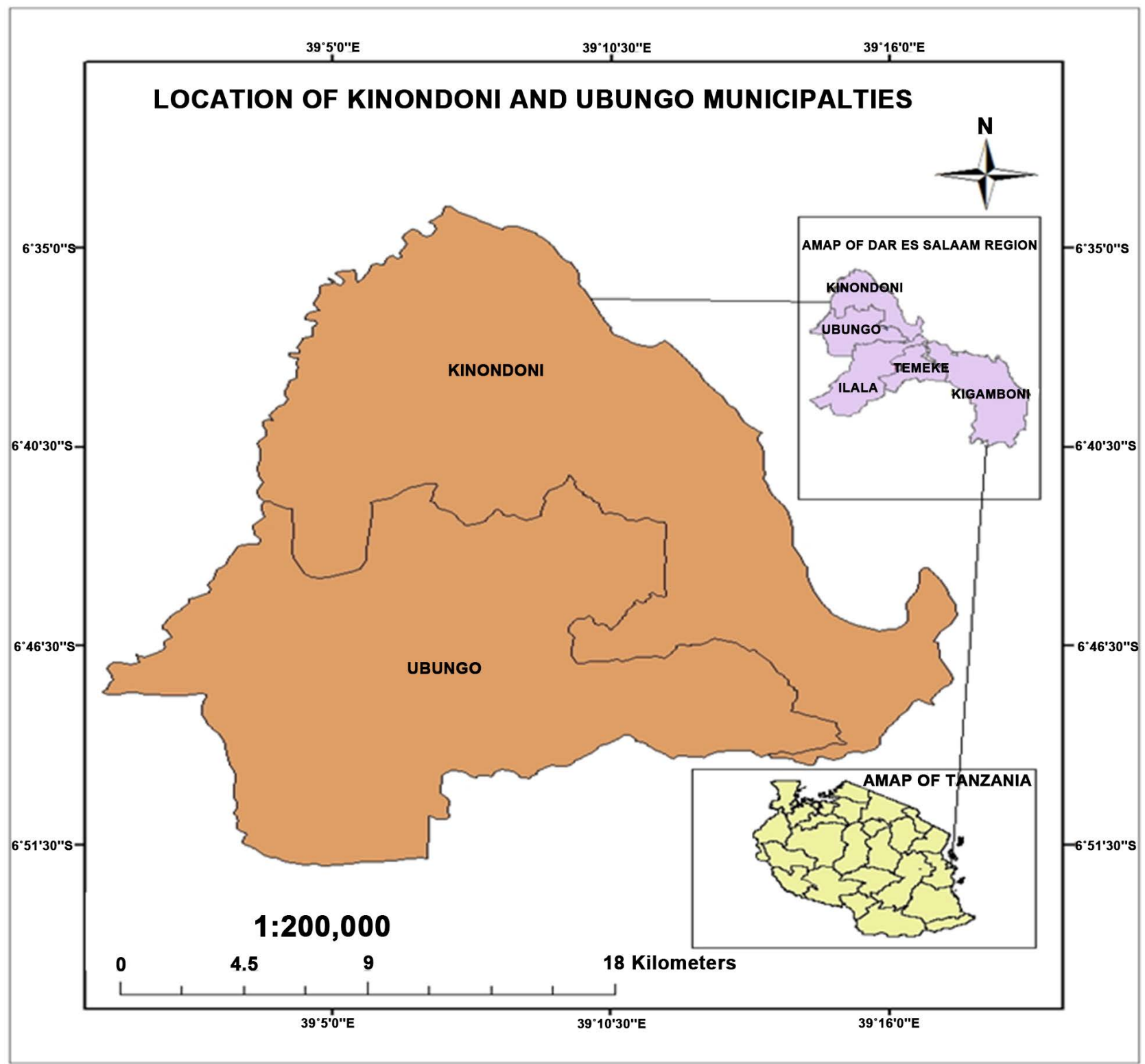

Figure 1. Map of ubungo and kinondoni municipalities.

The establishment of satellite towns has been extensively studied by various urban planning researchers. [10] pointed out that satellite towns are built for promoting well-being for citizens in the city. Also, they play an important role in promoting economic growth, creating employment and effective use of public services. Urban planners have been using different indicators to determine suitable locations of satellite towns. The commonly used indicators in selecting locations of satellite towns are socio-economic, health and distribution of income between different groups of households [11] [12] used the above indicators in selecting suitable locations of satellite towns by rating and ranking cities differently. Other indicators used are distances from the Central Business District (CBD) and population growth. The limitations of using these indicators include 
unsuitable locations of proposed satellite towns which ultimately fail to attract economic growth.

In order to effectively select suitable locations of satellite towns, unbiased, and effective techniques have to be employed. Saaty model or commonly known as Analytic Hierarchy Process (AHP) is a mathematical model used to solve complex decisions [13]. AHP model helps to find solution on complex issues that best suit the expected goals and challenges. Also, it provides for a comprehensive and rational framework by relating the selected elements to the overall goals and for evaluating alternatives. The best decision using AHP model is reached by modeling and characterizing the problem in a hierarchy manner. Modeling and characterization of a problem from general to multi-level is a way of ranking and organizing data and ideas that could be easily represented mathematically. The mathematical representation of data and ideas is based on assigning responsibilities to each element and integrating large amounts of data and information for the best decision making.

AHP has been extensively used for complex decision making by government, business, industry, healthcare and education [14]. According to [14], AHP model is first decomposed into a hierarchy level to easily comprehend sub-problems whereby each hierarchy is being analyzed independently. Once the hierarchy is analyzed and decomposed into sub-problems, the decision makers systematically evaluates used elements by comparing them with the corresponding impacts of the elements in the hierarchy. A numerical weight or priority is derived for each element in the hierarchy allowing elements to be compared in a rational and consistent manner. Finally, the numerical weights or priorities are calculated on each decision alternative. After the numerical priorities have been calculated a decision support tool is used to manipulate and analyze the geographical data. In this study, the AHP Model was used because it assists the decision maker to set up priorities on dealing with a complex problem and helps to reach the best decision. Also, it has the capability for checking the consistency of the decision maker's evaluations at the same time reducing the biasness in the decision making process. In this study, the AHP model was integrated with GIS technology in selecting suitable locations of satellite towns for Ubungo and Kinondoni municipalities in Dar es Salaam City.

\section{Data and Methodology}

The data used to select suitable locations of satellite towns in this study are land use, power lines, water pipe, elevation, slope, road network and telephone lines. The main reason for choosing such criteria is due to the fact that they are the controlling factors for urban development. The data were processed and a Digital Elevation Model map, a slope map, an elevation map, a road network map, a power line map, a telephone lines map and a water map were created. The maps were processed using AHP model where a multi-criterion expert decision support for land suitability for selected elements was determined. The weight on 
each element was assigned based on their importance. A pair wise comparison matrix, $n^{\text {th }}$ root of the product, weight, vector value, eigenvalue, Consistency Index (CI) and Consistency Ratio (CR) were calculated. Figure 2 shows the workflow of AHP used in this study.

\subsection{Calculation of Pair-Wise Comparison Matrix}

The calculation of a pair wise comparison matrix was based on the intensity of the elements and importance of each attribute which includes equal importance, somewhat important, more important, very important, and absolutely more important. If an attribute $A$ is absolutely more important than an attribute $B$ is rated as 9 , then $B$ is absolutely less important than $A$ and is rated as $1 / 9$. Based on this concept, the pair wise comparison matrix based on the importance of the selected attributes was computed. Table 1 shows the pair wise comparison matrix of the computed attributes based on their importance.

After computation of the pair wise comparison matrix, the $n^{\text {th }}$ root of the product value of each criterion was calculated using the Equation (1)

$$
N^{\text {th }} \text { Root }=\sqrt[n]{(\text { product value of the } 7 \text { elements })}
$$

where: $n$ is the number of total criteria used

Once the $N^{\text {th }}$ root of the product is calculated, the value obtained is used to calculate the weight of each criterion as shown in Equation (2)

$$
\text { Weight }=\frac{N^{\text {th }} \text { root of criteria }}{\text { Total value of } N^{\text {th }} \text { value }}
$$

The calculated $A=\pi r^{2} N^{\text {th }}$ roots and their corresponding weights of each criterion are shown in Table 2.

\subsection{Calculation of the Vector Value and the Eigenvalue}

After the $N^{\text {th }}$ root and the weight of each criterion have been calculated the vector value and eigenvalue $\left(\lambda_{\max }\right)$ were calculated and then used to compute

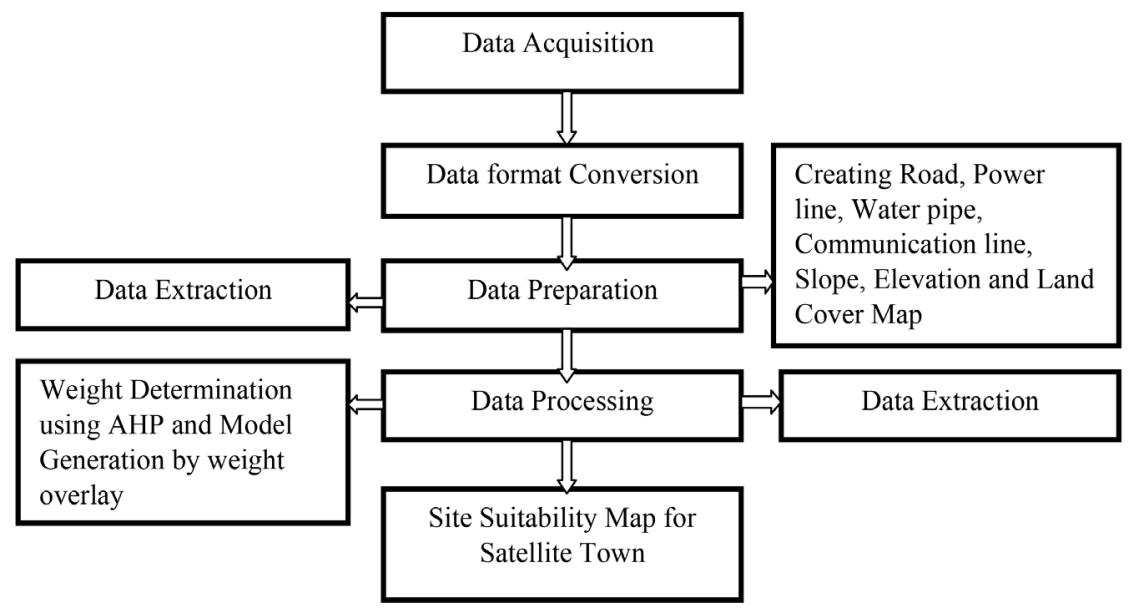

Figure 2. Schematic of work flow for the Methodology. 
Table 1. Pairwise comparison matrix.

\begin{tabular}{cccccccc}
\hline Criteria & Water & $\begin{array}{c}\text { Power } \\
\text { line }\end{array}$ & Road & $\begin{array}{c}\text { Commu } \\
\text { nication }\end{array}$ & $\begin{array}{c}\text { Land } \\
\text { Use }\end{array}$ & Elevation & Slope \\
\hline Water & 1 & 2 & 3 & 4 & 7 & 9 & 9 \\
Power line & $1 / 2$ & 1 & 3 & 4 & 6 & 8 & 9 \\
Road & $1 / 3$ & $1 / 3$ & 1 & 3 & 4 & 5 & 7 \\
$\begin{array}{c}\text { Commu } \\
\text { nication }\end{array}$ & $1 / 4$ & $1 / 4$ & $1 / 3$ & 1 & 3 & 6 & 7 \\
Land Use & $1 / 7$ & $1 / 6$ & $1 / 4$ & $1 / 3$ & 1 & 3 & 3 \\
Elevation & $1 / 9$ & $1 / 9$ & $1 / 7$ & $1 / 7$ & $1 / 3$ & $1 / 2$ & 1 \\
Slope & $1 / 9$ & $1 / 9$ & $1 / 7$ & $1 / 7$ & $1 / 3$ & $1 / 2$ & 1 \\
\hline
\end{tabular}

Table 2. The $N^{\text {th }}$ root and weight of each criterion.

\begin{tabular}{ccc}
\hline Criteria & Nth Root of Product Value & Weight \\
\hline Water & 3.90 & 0.36 \\
Power Line & 3.07 & 0.28 \\
Road & 1.73 & 0.16 \\
Communication & 1.15 & 0.10 \\
Land Use & 0.56 & 0.05 \\
Elevation & 0.32 & 0.03 \\
Slope & 0.24 & 0.02 \\
Total & 10.97 & 1 \\
\hline
\end{tabular}

the Consistency Index $(C I)$ and the Consistency Ratio $(C R)$. The eigenvalue of each criterion was determined by multiplying a pair wise comparison matrix value with the corresponding weight of each element. Then the mean of the eigen values is calculated. The Consistency Index $(C I)$ for a pair wise comparison matrix was calculated using Equation (3).

$$
C I=\frac{\lambda_{\max }}{n-1}
$$

where $\lambda_{\max }$ the eigenvalue and $\mathrm{n}$ is number of elements.

The Consistence Ratio ( $C R$ ) was calculated using Equation (4).

$$
C R=\frac{C I}{R I}
$$

where: $C I$ is Consistence Index and $R I$ is Random Index.

According to AHP model, a condition to attain a best decision is where the computed $C R$ is not greater than 0.1 . In this study, the calculated $C R$ was 0.05 which is below the AHP model threshold. Another important aspect when using AHP model to attain a best decision is creation of data model which is used for suitability analysis. In this study, the data model was created based on seven elements namely slope, elevation, land use, power line, water pipe, telephone 
lines and road network.

\section{Results and Discussions}

After data model was created, various suitability maps were produced including slope, elevation, communication line, power line, water and road network. Figures 3-9 show the suitability maps produced using the above mentioned elements.

The suitability maps produced were generated after the weighted values had been overlaid on all the re-classified criteria. The suitability maps for the satellite towns using the above mentioned elements were divided into five classes; highly suitable, moderately suitable, marginally suitable, not suitable and permanently not suitable. The AHP model was again used to select the suitable locations for satellite towns in respect of the selected elements. Figure 7 shows the final suitability map of satellite towns for Ubungo and Kinondoni Municipalities.

From Figure 9, the dark green areas represent highly suitable areas for satellite town's locations while the dark maroon color represents permanently unsuitable areas. The results obtained show that about $5.31 \%$ of the area was classified as highly suitable, $29.82 \%$ as moderately suitable, $24.27 \%$ as marginally suitable and $40.6 \%$ permanently unsuitable. The final suitability map of satellite town's locations was compared with the locations of satellite towns proposed by the Dar es Salaam Master plan of 2016 as shown on Figure 10.



Figure 3. Slope suitability map. 


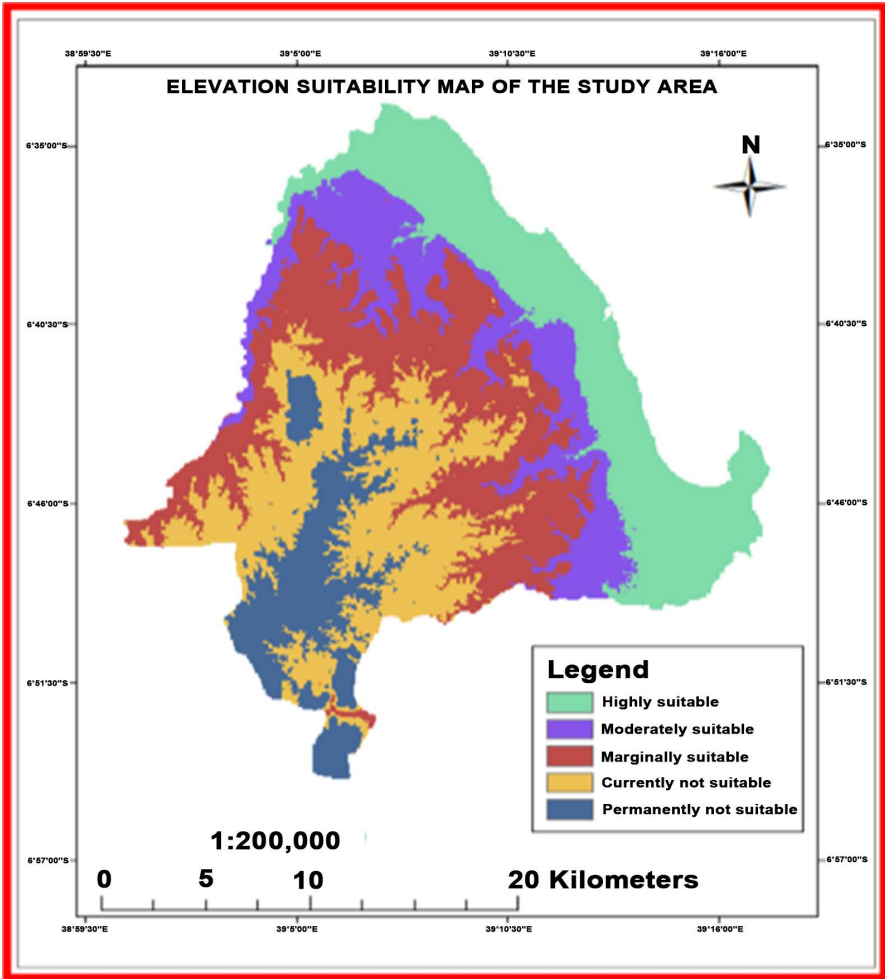

Figure 4. Elevation suitability map.

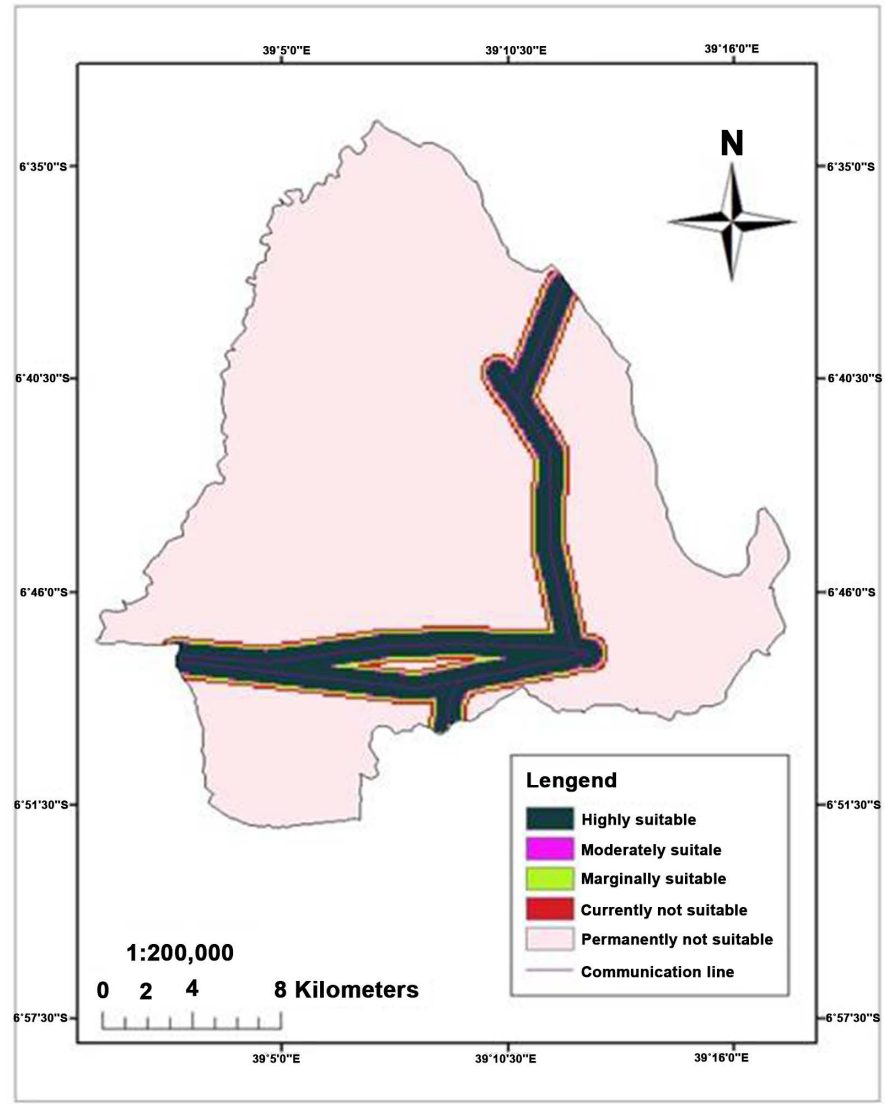

Figure 5. Telephone lines suitability map. 


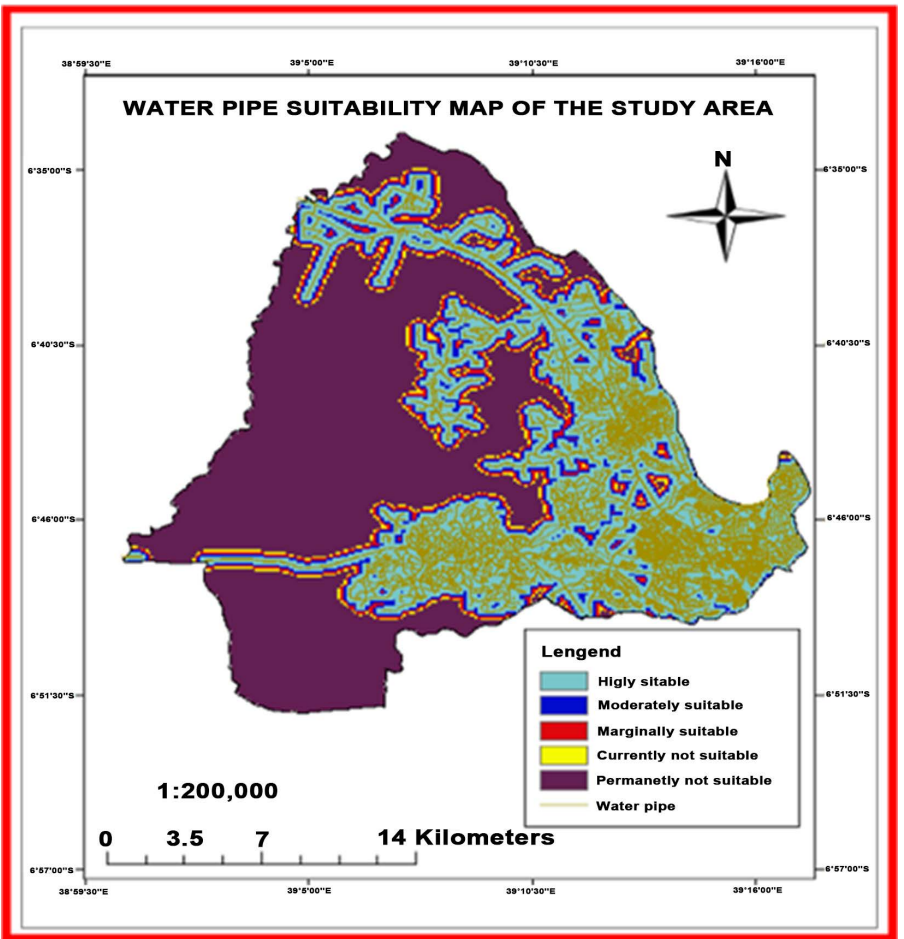

Figure 6. Water suitability map.

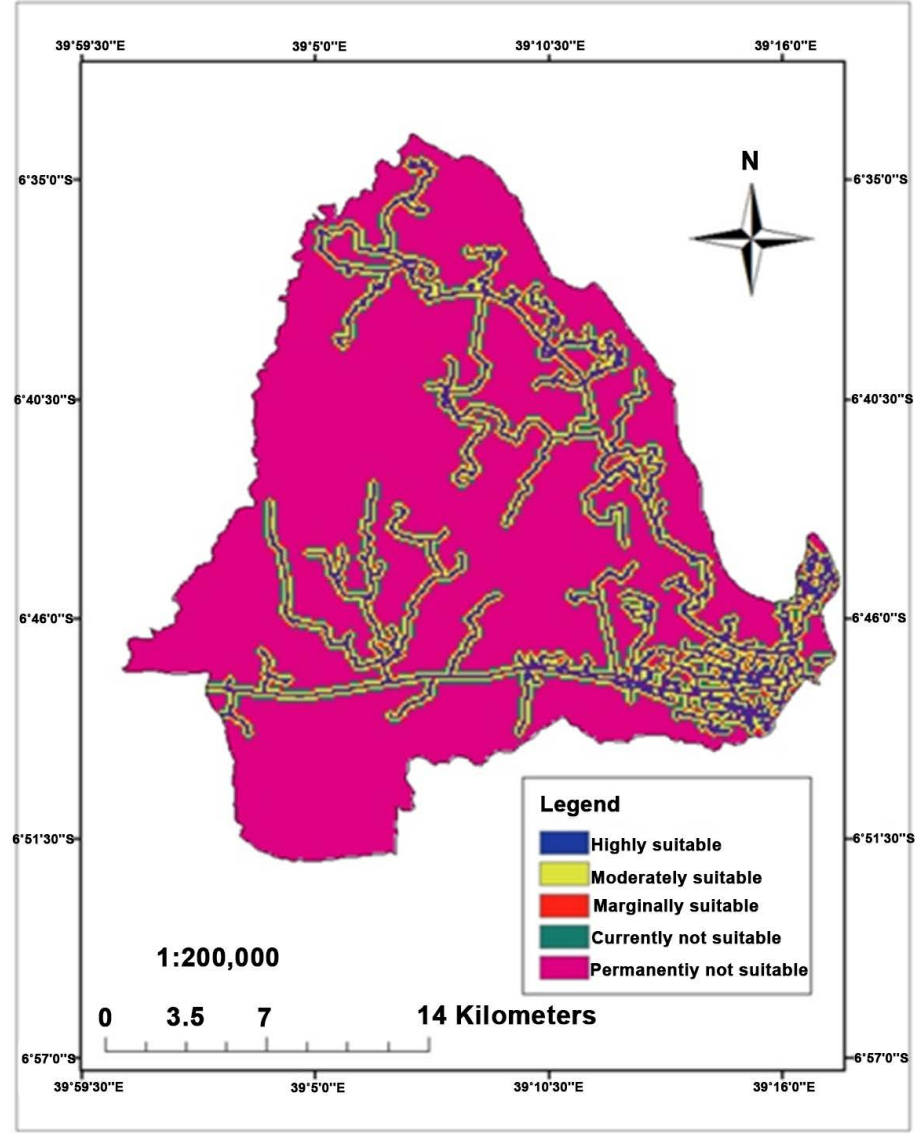

Figure 7. Power line suitability map. 


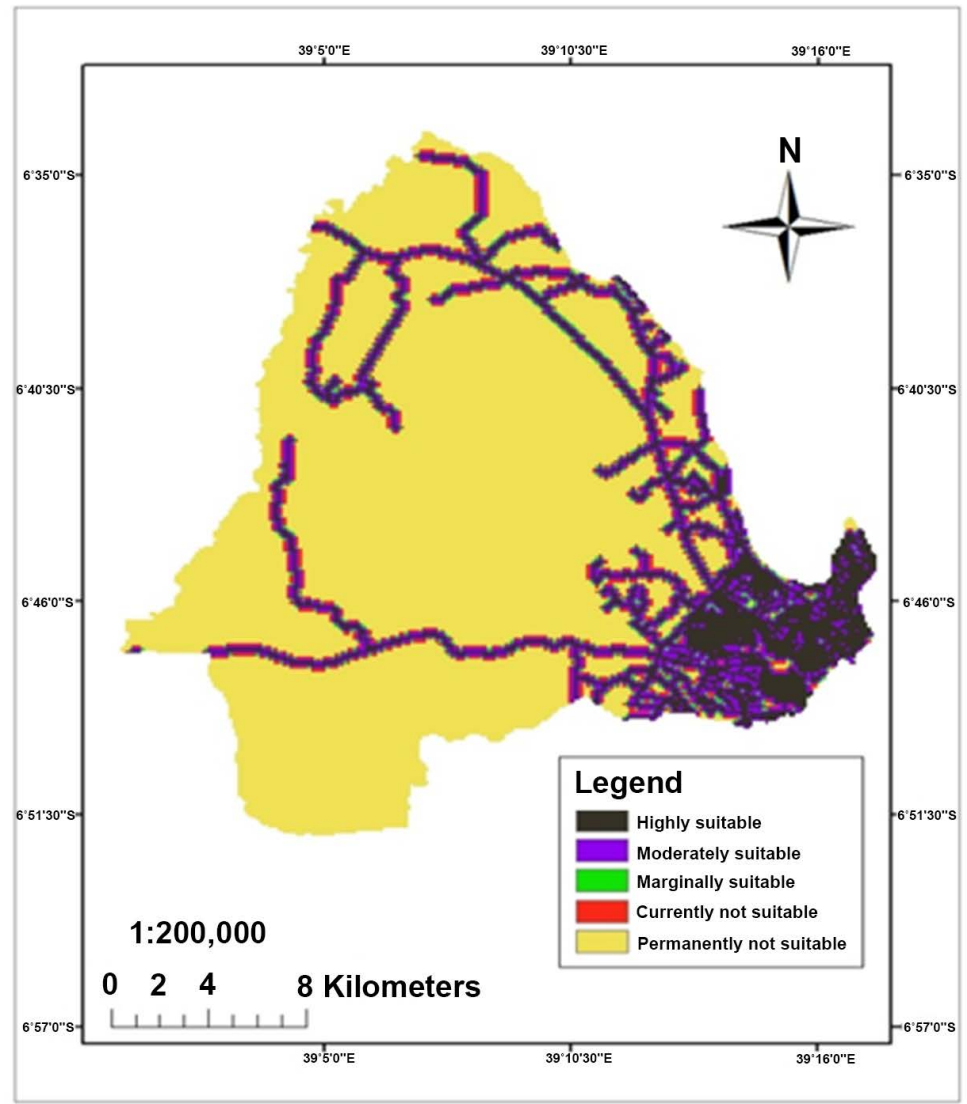

Figure 8. Road network suitability map.

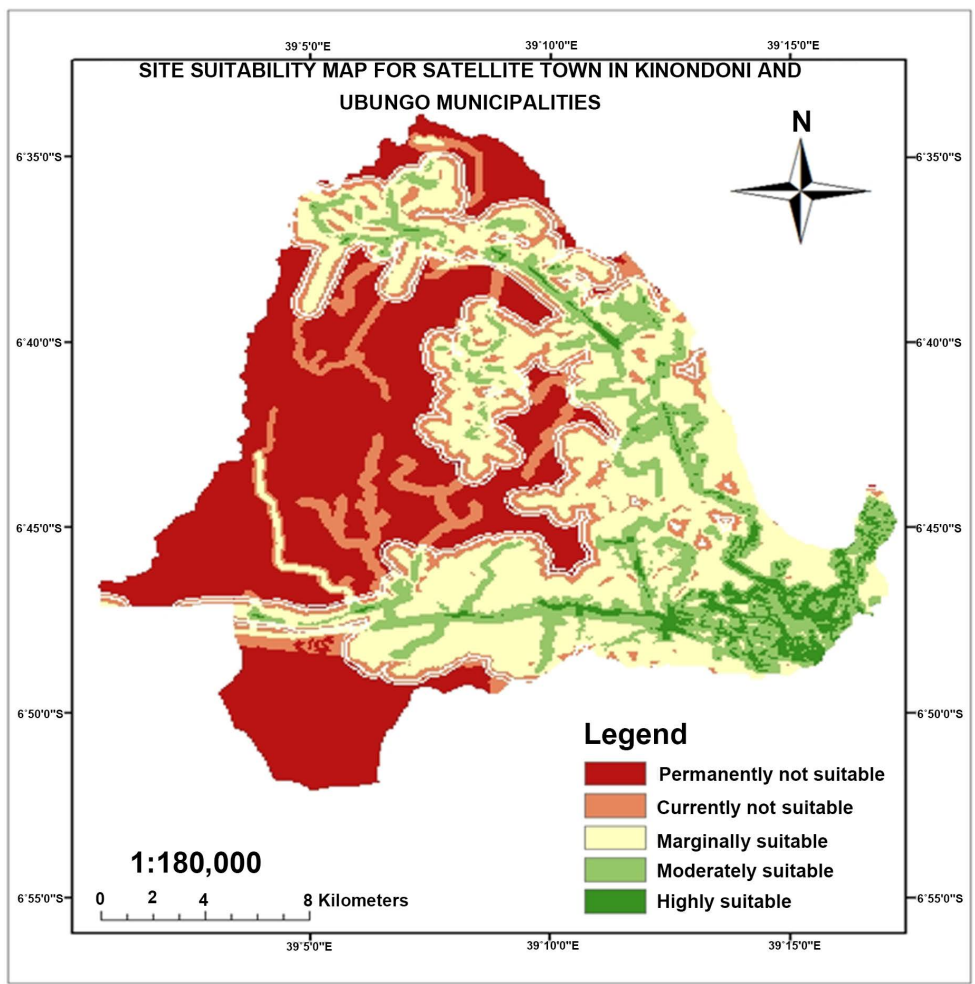

Figure 9. Final suitability map of satellite towns. 


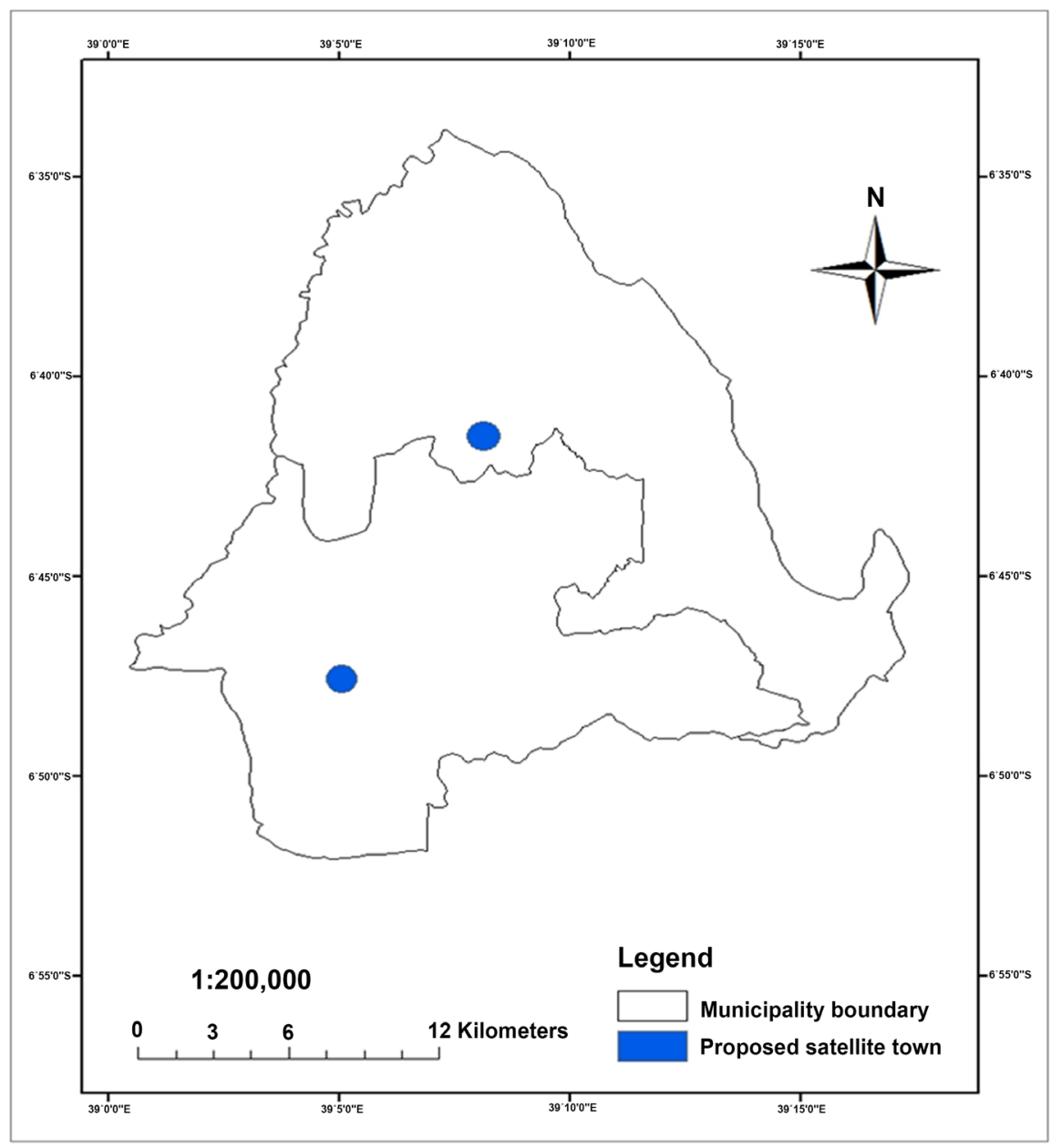

Figure 10. Proposed locations of satellite towns from Dar salaam master plan.

However, it must be observed that, the dark green area depicted by AHP model at the Dar es Salaam CBD was due to the concentration of the land use, power line, water pipe, telephone lines and road network used in the Saaty Model. Since satellite towns are usually located at the outskirts of the CBD, the dark green along these areas are the most highly suitable locations.

\section{Assessment of Satellite Towns Locations}

The business communities are interested to understand how and where the satellite towns have been located so that they can effectively plan for their investments. The assessment of the locations of satellite towns determined using AHP model and GIS was compared with the proposed locations from the proposed Dar es Salaam master plan. The comparison was done by superimposing the suitability map produced using Saaty Model with the proposed satellite town locations from the Dar es Salaam master plan. Figure 10 shows the locations of proposed satellite towns from Dar es Salaam master plan while Figure 11 below shows the superimposed locations of the satellite towns on the suitability map produced using Saaty Model. Figure 10 shows that the locations of the 


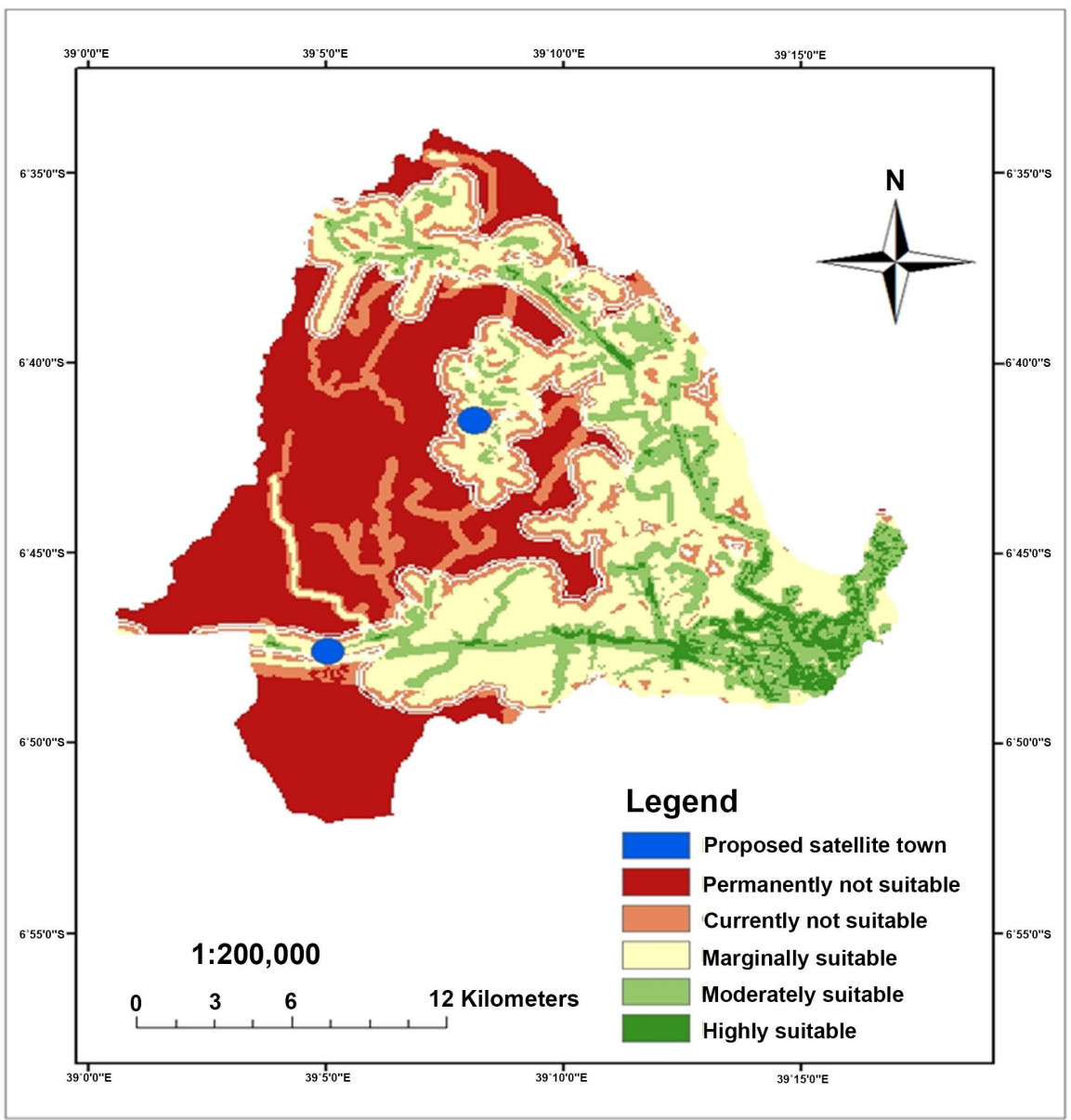

Figure 11. Suitability map superimposed with proposed locations of satellite towns from 2016 Dar es Salaam Master plan.

satellite towns locations of the satellite towns from the proposed Dar es Salaam master plan are located on marginally suitable areas. The Areas shown by dark green colour are to be selected as suitable locations of satellite towns for Ubungo and Kinondoni municipalities.

\section{Conclusion}

This study has shown that locations of suitable satellite towns determined using Saaty model was found to be on highly suitable areas whereas locations of satellite towns from proposed Dar es Salaam master plan were found to be located on marginally suitable areas. Therefore, this study demonstrated that Saaty Model if integrated with GIS can effectively be used by town planners to select unbiased suitable locations of satellite towns in big Cities.

\section{References}

[1] NBS (2012) National Bureau Statistics Population Distribution. NBS, 7-9.

[2] IGC (2012) Urban Growth. Internal Migration and Urbanization in Tanzania, C-40211-TZA-1, 30. 
https://www.theigc.org/wp-content/.../09/Wenban-Smith-2015-Working-paper-1.p df

[3] AFDB (2015) Tracking African Progress in Figures. https://www.afdb.org/fileadmin/uploads/afdb/Documents/Publications/Tracking_A frica\%E2\%80\%99s_Progress_in_Figures.pdf

[4] CTI (2012) A Situation Analysis Report to Examine the Charging Procedures of Wharfage Charges for Cargo Passing at Dar es Salaam Port. CTI, 39.

[5] Wright, C. (1995) Gender Awareness in Migration Theory: Synthesizing Actor and Structure in Southern Africa. Development and Change, 26, 771-791. https://doi.org/10.1111/j.1467-7660.1995.tb00574.x

[6] Aloyce, M. (2002) Rural-Urban Dynamics: Modelling and Predicting Land Use Changes in Peri-Urban Interface in Dar Es Salaam City, Tanzania. Third International Human Dimensions Workshop: Human Dimensions of Urbanisation and the Transition to Sustainability, Bonn, Germany.

http://www.ihdp.uni-bonn.de/ihdw02/sec_week.htm

[7] Kasala, S.E. (2015) Areturn to Master Planning in Dar es Salaam. A Global Journal of Human Social Science (B), XV II.

[8] Taylor, G.R. (1915) Satellite Cities: A Study of Industrial Suburbs. D. Appleton and Company, New York and London, 355.

[9] Evans, D. and Evans, W. (2007) The Complete Real Estate Encyclopedia. The McGraw-Hill Companies, Inc., New York, 512.

[10] Merlin, P. (2013) New Town and European Spatial Development. America Journal of Rural Development, 1, 81-90.

[11] Biske, V., Rivza, B., Rivza, P. and Rivza, S. (2009) The Causes of Economic Downturn, the Assessment of Stabilisation Programme in Latvia. 251-265.

[12] Savageau, D. (2007) Places Rated Almanac. Places Rated Books LLC., Washington, DC, 662 .

[13] Saaty, T.L. (1980) The Analytic Hierarchy Process. McGraw-Hill, New York, 8.

[14] Theobald, D.M. (2007) GIS Concept and ArcGIS Methods. 3rd Edition, Conservation Planning Technologies, Colorado. 